\title{
Comparison Between Coblation Assisted Tonsillectomy Versus Conventional Tonsillectomy Regarding the Postoperative Pain and Bleeding
}

\author{
Stefan Konsulov ${ }^{1}$, Spas Konsulov ${ }^{2}$, Karen Dzhambazov ${ }^{2}$, Petar Kopanov ${ }^{3}$ \\ ${ }^{1}$ Department of Ear Nose and Throat Disease, University Hospital Kaspela, Medical Univesity-Plovdiv, Plovdiv, Bulgaria \\ ${ }^{2}$ Deaprtment of Ear Nose and Throat Disease University Hospital St. George Plovdiv, Medical University-Plovdiv, Plovdiv, Bulgaria \\ ${ }^{3}$ Faculty of Mathematics and Information, University of Plovdiv Paisii Hilendarski, Plovdiv, Bulgaria
}

Email address:

skonsulov@abv.bg (S. Konsulov), stkonsulov@gmail.com (S. Konsulov)

\section{To cite this article:}

Stefan Konsulov, Spas Konsulov, Karen Dzhambazov, Petar Kopanov. Comparison Between Coblation Assisted Tonsillectomy Versus Conventional Tonsillectomy Regarding the Postoperative Pain and Bleeding. International Journal of Otorhinolaryngology.

Vol. 3, No. 1, 2017, pp. 1-5. doi: 10.11648/j.ijo.20170301.11

Received: March 27, 2017; Accepted: April 5, 2017; Published: April 26, 2017

\begin{abstract}
Background: The tonsillectomy is one of the most common surgical procedure in the world. Common complications are postoperative pain and bleeding. Coblation tonsillectomy is recent method of these surgical procedure and there are few publications in the literature and published information which are focused on the specific aspects of this surgical techniques or early postoperative complications. This study compare coblation and traditional tonsillectomy techniques in view of their advantages and complications. methods: In our prospective study type we include 60 children and adolescents, divided equally:30 conventional tonsillectomy versus 30 surgically treated with Coblation II system Arthrocare (Smith and Nephew). We compared the postoperative pain and intraoperative bleeding in the patients underwent surgery within conventional method versus coblation assisted tonsillectomy. To measure the pain we used visual-analogue scale of Wong-Baker with face expressions ( 0 no hurt; 10-hurts worst). We follow-up the level of pain in the day 1,2 and 7 after the surgery Estimated blood loss for coblation tonsillectomy was calculated by deducting the total amount of blood in suction jar with estimate saline used for the surgery. Results: Average age of participants surgically treated with conventional method group are $6,87 \pm 3,01$. In the group where we used coblation method the average age of participant were $8.16 \pm 4,74$. We found statistically significant differences ( $p$-value $<0.0001)$ in these parameters in both surgical techniques: the pain is less weak in intensity in the patients treated with the Coblation method in all the three days. In regard of intraoperative bleeding we found statistically significant difference between both methods ( $\mathrm{p}$-value $-9.3132 * 10^{-10}$ ). The average bleeding in the conventional method is $97,5 \mathrm{ml} \pm 12,12$ $\mathrm{ml}$, comparing with the coblastion-assisted tonsillectomy the average intraoperative bleeding is $27,1 \mathrm{ml} \pm 14,28 \mathrm{ml}$. Conclusions: This study revealed a significantly less intraoperative or postoperative complications and morbidity in coblation tonsillectomy in comparison with traditional method. Coblation was associated with less pain and quick return to normal diet and daily activity. These findings addressed coblation tonsillectomy as an advanced method.
\end{abstract}

Keywords: Coblation, Tonsillectomy, Complications

\section{Introduction}

Tonsillectomy is one of the most common surgical procedure in Bulgaria performed by the ENT surgeons. Most literatures mentioned that the tonsillectomy operation is one of the most common major pediatric surgical intervention with recorded of mortally and also morbidity. In Germany every $25^{\text {th }}$ patient, who underwent tonsillectomy are reported with postoperative bleeding. Reports for complications and even death equally disturb patients and Surgeons. One of the most common complain after tonsillectomy is postoperative pain. Postoperative pain make the recovery process more difficult and slow in time. The patients can't start eat and drink early after the surgery especially children. $[1,2,3,5,7$, $14,15,16,18]$

Coblation 
A minimally invasive, low thermal technology for effective dissection and removal of soft tissue, Coblation technology is ideal for such ENT procedure as tonsillectomy, adenoidectomy, reduction of hypertrophic nasal turbinates, laryngeal polypectomy and lesion debulking, soft pallet, snoring and sinus surgery. While the most radiofrequencybased on surgical products, such as laser and electrosurgical devises, use imprecise heat-driven process to remove or cut tissue, Coblation Plasma technology creates a controlled, stable plasma field to precisely remove tissue at a low relative temperature, resulting in minimal thermal damage to surrounding tissues $[1,7,13]$.

The coblation method is patented in 1997 from ArthroCare. This surgical technique of coblation tonsillectomy is based on bloodless dissection in the tonsillar field by using Arthrocare Evac 70 Arthro Wand. Using this technique it has found practically bloodless field through the surgery procedure and the overall blood lost is not significant. [1, 4, 8]

Blackburn and Ribble Valley Health Authority own the biggest tonsillectomy record with coblation II system in UK and probably the biggest in the world, approximately 850 cases. Using these data we can calculate the complications followed this new surgical procedure and compare it with our standard method of tonsillectomy. Secondary complications or bleeding are due to infections in the tonsillar field. The contractions of the pharyngeal muscles are responsible for physiological cleaning of tonsillar field and also the infections can be caused by the contamination with food in that area. The muscular failure due to severe pain or volitional immobilization are obstacles in physiological cleaning of the tonsillar field. This increased the chances to develop infection and bleeding after that. Considering secondary bleeding, coblation tonsillectomy is more reliable comparing to the dissection tonsillectomy. The advantages of this technique are: low level of postoperative pain and discomfort, early return to normal diet physical activities and also small amount intraoperative blood loss. Therefore the postoperative period is shorter than conventional method and also better postoperative quality of life. $[3,14,17]$

\section{Aim of the Study}

Establishment of coblation assisted tonsillectomy as a routine surgical method in children with chronic tonsillitis or tonsillar hypertrophy and OSA.

\section{Methods}

Our study is prospective and comparative, involving 60 children in the age of 3-18y. The patients were divided into groups on equal basis according to the surgical techniqueGroup 1 and Group 2. This study on 60 person was performed in the period of 2014-2017. The project was approved with protocol of ethic commission in the Medical University of Plovdiv. The children were included in the study after the consent form was sign by the Parents.
Including criteria: Paradise criteria for tonsillectomy [12]

Minimum frequency of sore throat episodes-7 or more episodes in the preceding year, OR

5 or more episodes in each of the preceding $2 \mathrm{y}$

3 or more episodes in each of the preceding $3 \mathrm{y}$

Clinical features (sore throat plus the presence of one more qualifies episodes as a counting episode: Temperature > $38.3^{\circ} \mathrm{C}$, OR $101^{\circ} \mathrm{F}$

Cervical lymphadenopathy (tender lymph nodes or $>2 \mathrm{~cm}$ ), OR

Tonsillar exudate, OR

Positive culture for group A b-hemolytic streptococcus

: sore throat

: bad breath, which may related with cryptic tonsils

: enlarge and tender neck lymph nodes

: Hypertrophy- causing upper airway obstruction (obstructive sleep apnea)

Ever, dysphagia (trouble swallowing), sleep disorders, or cardiopulmonary

complication.

: Peritonsillar abscess

Excluding criteria: different age group

: very young age under 4

: presence acute infection

: refusal of surgery

: blood diseases

: unilateral tonsillar hypertrophy

: known blood disease

On the day of admission the patients were examine by ENT specialist and history was taken. They were questioned about any current acute diseases, any history of blood disease in the family, any known allergies, medication and opioid medication also ongoing menstrual cycle in older female patients at the day of admission. The venous blood was taken from the patients and sent in the laboratory for full blood count and time of bleeding and coagulation. After the blood results the patients were referred to pediatric department and anesthetist for consultation and general anesthesia. All the patients and parents were informed about the upcoming surgery, benefits and further complication were discussed, after that they sign a consent form.

The conventional method includes extracapsular blunt dissection with bipolar diathermy for haemostasis. In the coblation tonsillectomy we used Coblator II system ArthroCare (Smith and Nephew) Evac 70 wand for extracapsular dissection with also irrigation and haemostasis.

We evaluate the objective and subjective complains by using questionnaire form and visual analogue scale of WongBaker with facial expression, for both methods coblatorassited tonsillectomy and conventional method 0 - no hurt, 10 hurt worst.

We used general anesthesia for all the patients in the study. -Subjective complains:

-Estimated blood loss for coblation tonsillectomy was calculated by deducting the total amount of blood in suction jar with estimate saline used for the surgery.

The estimate blood loss for conventional tonsillectomy 
was calculated by deducting the total amount of blood in suction jar.

-Postoperative bleeding- early bleeding to $24 \mathrm{~h}$ after the surgery and late bleeding after $24 \mathrm{~h}$. In the morning ward round 8-9h O'clock we examined the wound, the overall condition of the patients and any history of bleeding. All the data were correctly filled. Any events of postoperative bleeding were reported in the study. We used combination of paracetamol and ibuprofen with the appropriate dosage for around a week if needed.

- Healing of the wound was reviewed and on the $1^{\text {st }}, 2^{\text {nd }}$ and $7^{\text {th }}$ day. We were reviewed the postoperative wound and measured the fibrin deposits.

All the patient who were admitted for tonsillectomy in University Hospital St. George, Plovdiv and University Hospital Kaspela, Plovdiv stayed in the ward minimum for two days. All the patients who were in good overall condition start to eat and drink in the evening after the surgery have no signs of bleeding were discharged at the second day after the surgery. All the patients were came in outpatient clinic on the 7th day after the surgery to be followed up (measure the pain and postoperative wound). The statistical analysis was based on "sign test" and have done by using Mathematic Version 11.

\section{Results}

The patients who were included in the study were 60 and divided on two equal groups:

30 person with conventional dissection tonsillectomy versus 30 patients who were surgically treated with coblation method. The average age of patients were $6,87 \pm 3,01$ in the group one. In the second group where we used coblation II system Arthrocare Evac 70 wand average age was 8,16 $\pm 4,74$.

There weren't any early or late bleeding in the group of coblation assisted tonsillectomy, there were two cases with postoperative bleeding in the group of conventional method.

Regarding the pain: on the first day after the surgery in conventional method we have average level of pain 7,4 $\pm 0,93$ according to the Wong-Baker pain scale. The Wong-Baker FACES Pain scale is often helpful for assessing persons with moderate to severe dementia or children who have lost much of their ability to use language to describe pain. This scale uses faces from happy to tearful to demonstrate how a person might be feeling. It should be used only after the person in pain has demonstrated inability to understand the " 0 " to " 10 " pain scale [6].

The patients who were surgically treated with the conventional method received ibuprofen and paracetamol for around a week.

On the second day after the surgery with the same method the level of pain was $5,66 \pm 0,92$. On the seven day was $3,86 \pm 1,47$. Regarding to coblation assisted tonsillectomy the average level of pain on the $1^{\text {st }}$ day was $2,6 \pm 1,19$. On the second day the level of pain was $3,06 \pm 1,48$. On the 7 th day the pain was $2,2 \pm 1,27$. (figure 1 ). Few hours after the surgery the patients received ibuprofen and paracetamol after that in most cases the pain regressed spontaneously.

Table 1. Average values on the basic indicators in the both surgical methods; Group1 - Cold steel dissection tonsillectomy; Group2 - Coblator assisted tonsillectomy.

\begin{tabular}{|c|c|c|c|c|c|c|c|c|}
\hline & \multicolumn{2}{|c|}{ Pain 1-st day } & \multicolumn{2}{|c|}{ Pain $2^{\text {nd }}$ day } & \multicolumn{2}{|c|}{ Pain $7^{\text {th }}$ day } & \multicolumn{2}{|c|}{ Intraoperative bleeding $\mathrm{m}$} \\
\hline Group & Group1 & Group2 & Group1 & Group2 & Group1 & Group2 & Group1 & Group2 \\
\hline Average & 7.4 & 2.6 & 5.66 & 3.06 & 3.86 & 2.2 & 97.5 & 27.1 \\
\hline $\mathrm{SD}$ & \pm 0.93 & \pm 1.19 & \pm 0.92 & \pm 1.48 & \pm 1.47 & \pm 1.27 & \pm 12.13 & \pm 14.28 \\
\hline
\end{tabular}

There are statistically significant differences in the conventional versus coblation tonsillectomy regarding the: $1^{\text {st }}$ day pain ( $p$-value- $9.3132 * 10-10), 2^{\text {nd }}$ day pain ( $p$-value$\left.7.4505^{*} 10-9\right)$ and $7^{\text {th }}$ day pain (p-value- 0.00006 ); Regarding the pain on the $1^{\text {st }}$ day and $2^{\text {nd }}$ day the values are so small that we should exclude the chance possibility. The conclusion shows that the two methods are significantly different and these results are not due on chance. They are resulted on two different methods.

Regarding the intraoperative bleeding there is statistically significant difference between both methods ( $p$-value 9.3132*10-10) Avarage blood loss in the conventional method is $97,5 \pm 12,13 \mathrm{ml}$ and $27,1 \pm 14,28 \mathrm{ml}$ in the coblation assited tonsillectomy.

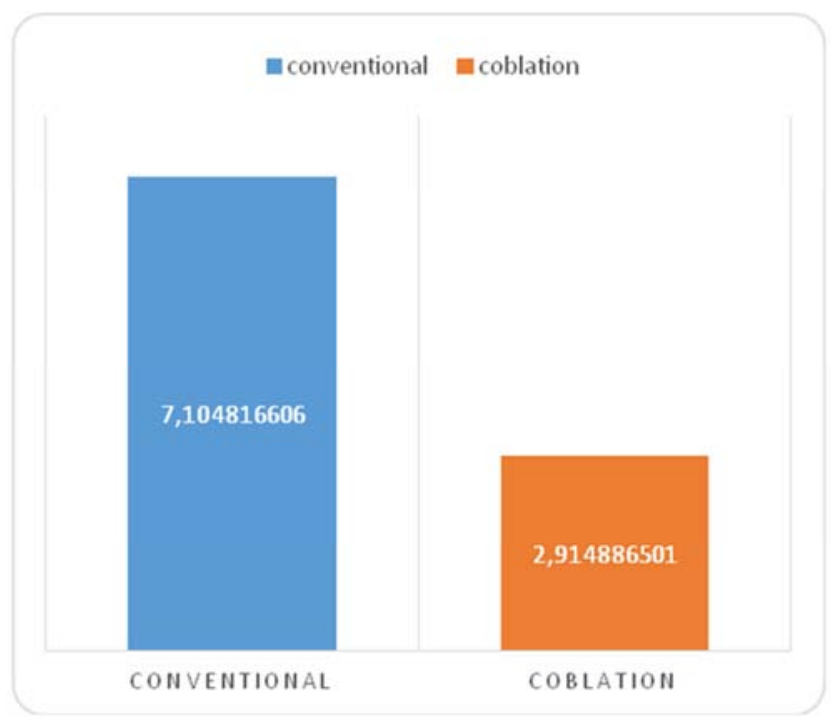

Figure 1. Postoperative pain on the $1^{\text {st }}$ day comparing conventional tonsillectomy and coblator-assisted tonsillectomy. 
Pain on the $1^{\text {st }}$ day after the surgery is significantly less weak as feeling in the coblation group vs the conventional tonsillectomy group.

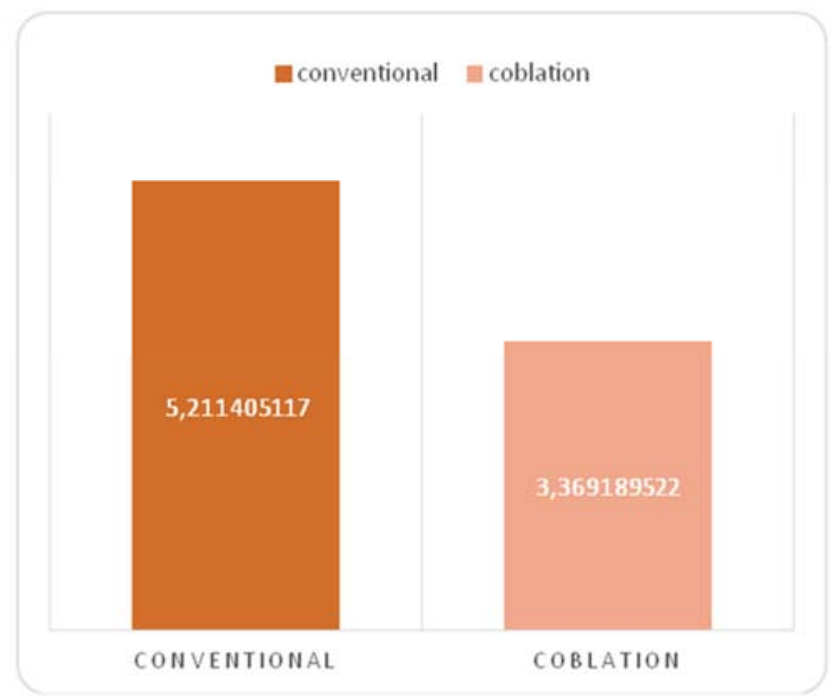

Figure 2. Postoperative pain on the 2nd- day comparing conventional tonsillectomy and coblator-assited tonsillectomy.

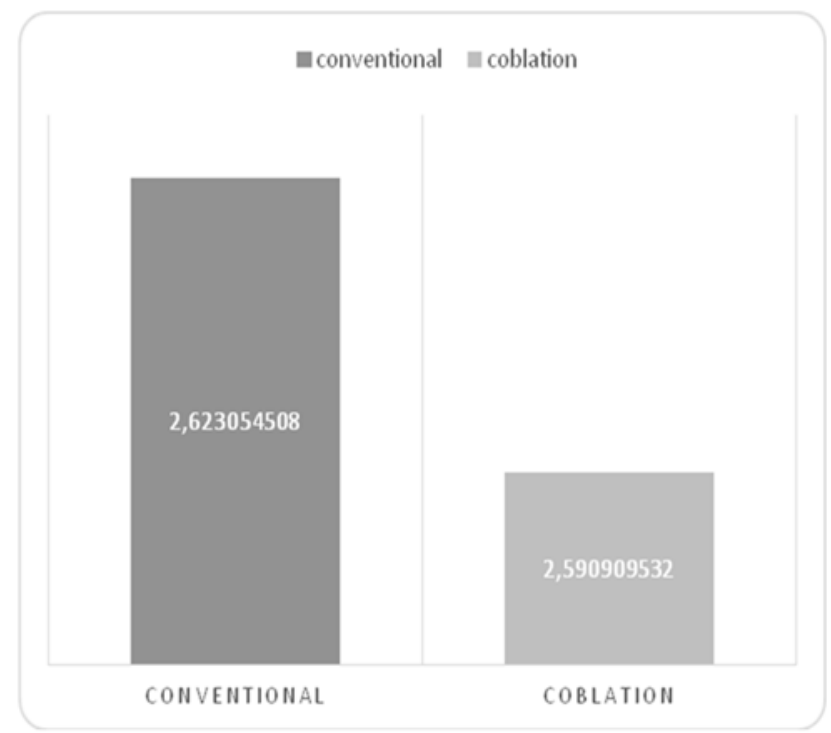

Figure 3. Postoperative pain on the 7th- day comparing conventional tonsillectomy and coblator-assisted tonsillectomy.

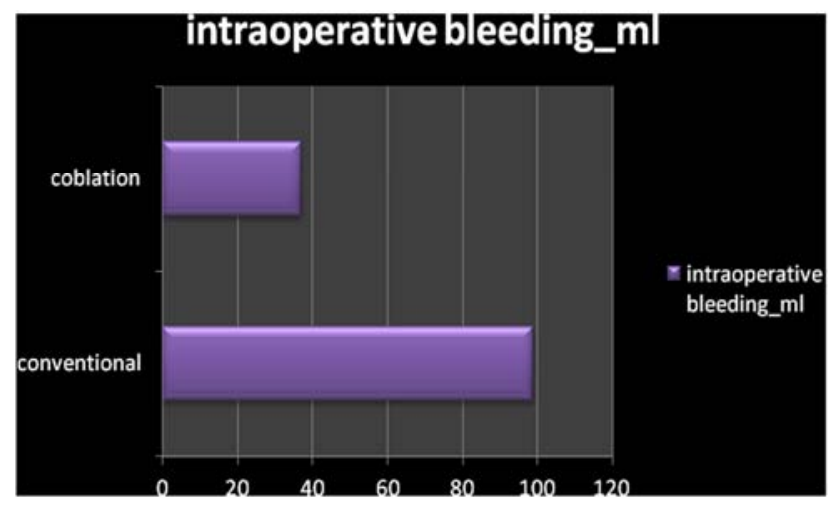

Figure 4. Intraoperative bleeding comparing both methods.
Intraoperative bleeding is significant less in the patients on who were performed surgery with Coblation II Arthrocare Eavac 70 wand comparing with conventional method.

\section{Discussion}

Tonsillectomy is one of the most common surgery procedure performed in Bulgaria. The tonsillectomy surgery is commonly the first surgery ever in childhood. It is commonly be related with different type of complications. Postoperative pain can lead to difficult intake of food and liquids which therefore can delay the healing of the wound and prolonged the restorative period. Postoperative bleeding is very serious complication and even can lead to death. Bleeding in the throat can hide a high risk of aspiration especially in children or even developing hemorrhagic shock $[1,4,8]$.

In our study the postoperative pain in patients who undergoing coblation assisted tonsillectomy have a significantly low pain on the $1^{\text {st }}, 2^{\text {nd }}$ and $7^{\text {th }}$ day comparing with conventional method. The average pain score in all three days between both groups have a significant difference. The patients who were treated surgically with the coblation method on the $1^{\text {st }}$ postoperative day have 4,8 points lower pain on the $2^{\text {nd }}$ day 2,6 points lower pain and 1,64 points on the $7^{\text {th }}$ day according to the Wong-Baker visual analogue scale. In 2012 Wagner and assistant conduct the same study in the "Alfred Krupp von Bohlen und Nalbach"Krankenhaus in Essen Germany on 376 Patients with (conventional tonsillectomy) and 94 patents who were surgically treated with coblation method. The average age was $15,6 \mathrm{y}$ in the control group and 15,7 $\mathrm{y}$ in the other group. The significant lower postoperative pain was observed in the coblation group versus conventional tonsillectomy $(0,9$ vs 6,4 points according to the visual analogue scale). In the Wagner study they found postoperative bleeding in $5,32 \%$ of the patients who undergoing coblation tonsillectomy and 5,05\% postoperative bleeding with the conventional method. There weren't statistically significant difference in both groups comparing this indicator $(\mathrm{p}=1.00)(16)$ the same as our study. We have in mind all the possible reasons that can cause a postoperative bleeding: postoperative pain, postoperative infection. [16].

Regarding postoperative bleeding in the group of conventional method there were only two cases with bleeding which were treated conservatively in the ward with antibiotics and pain killer due to suspicious of postoperative infection. In the other group where we used coblation method we didn't have postoperative bleeding. There weren't statistically significant difference regarding these two factors in both groups.

Polites et al. are measured postoperative pain into 19 patients on age between $16 \mathrm{y}$ and $41 \mathrm{y}$ and have found that postoperative pain on the first day was 3 points lower by using coblation method. On the $2^{\text {nd }}$ and 3 th day the pain was also significantly lower. They measured the pain using visual analogue scale. [13]. 
In 2006 Noordzij et al. are measured postoperative sense of pain into 48 adult patients who were surgically treated with coblation II system Arthrocare Evac 70 wand (Smith and Nephew) and monopolar electrocautery. In this study they also found a significant lower pain in the coblation method with 2 points lower pain comparing with the other group. Fourteen days after the surgery the postoperative pain was also significant lower in the group of coblation comparing to the other group. This study have similar results regarding the coblation tonsillectomy. [11].

In 2007 Mitic et al. performed prospective single blind, randomized controlled trail including 40 patients on the age between $4 y-12 y(16-60 \mathrm{~kg})$ with coblation tonsillectomy and dissection tonsillectomy with bipolar diathermy haemostasis. Primary outcomes were scored for postoperative pain, nutrition, activity and use of analgesia for each of the $10^{\text {th }}$ postoperative days. The groups were statistically comparable by age weight and operation type. Intraoperative bleeding was significantly less in the coblation group. We can confirm that we have similar results regrading intraoperative bleeding where we have approximately $70 \mathrm{ml}$ less blood loss in the coblation group comparing with the conventional group method. [10].

Mohammadreza et al. are conduct double-blind randomized study type case-control in the period of 20072008 with coblator II system Arthrocare and conventional method. They have found statistically significant difference regarding the postoperative pain. ( $p$-value $<0.01$ ). In regard of postoperative bleeding they haven't found any significant difference between the two groups. [2]. In our results we can confirmed the same findings such as this study [9].

In regard of intraoperative bleeding they have found statistically significant difference $(p<0.05)$, between both methods in favor of coblator-assisted tonsillectomy the same as our results.

\section{Conclusion}

In our study we have found, that coblation assisted tonsillectomy is less harmful and effective alternative method versus the traditional dissection tonsillectomy. Coblation assisted tonsillectomy comparing with the other methods do not lead to deep burning or damaging of surrounding tissues, which is not predisposing factor for postoperative infection and bleeding. Thus significantly reduce the postoperative pain, lead to better postoperative life quality, faster recovery and healing of postoperative wound.

\section{References}

[1] Георгиева Н., Златанов Хр., Цветков В. Тонзилектомия съвременни оперативни техники. Международен бюлетин по оториноларингология, 2012, 1:19

[2] Balbani APS. Personagens da História da Otorrinolaringologia. Arq. Int. Otorrinolaringol. 1998; 2(2):54
[3] Blakley BW, Magit AE. The role of tonsillectomy in reducing recurrent pharyngitis: a systematic review. Otolaryngol Head Neck Surg. 2009; 140: 291-297.

[4] Burton MJ, Doree C. Coblation versus other surgical techniques for tonsillectomy. Cochrane Database Syst Rev. 2007; 18(3): CD004619.

[5] Haddow, K., M. L. Montague and S. S. Hussain (2006). "Posttonsillectomy haemorrhage: a prospective, randomized, controlled clinical trial of cold dissection versus bipolar diathermy dissection." J Laryngol Otol 120(6): 450-4.

[6] Hockenberry MJ, Wilson D, Winkelstein ML: Wong's Essentials of Pediatric Nursing, ed. 7, St. Louis, 2005, p. 1259.

[7] Johnson LB, Elluru RG, Mayer III CM. Complication of adenotonsillectomy Laryngoscope 2002;112:35-37.

[8] Kay DJ, Mehta V, Goldsmith AJ: Perioperative adenotonsillectomy management in children: Current practices. Laryngoscope 113:592-597, 2003.

[9] Mohammadreza O, Behrouz B, Navid O, Ahmad RO, Seyed A, Ghazizadeh $\mathrm{H}$, Coblation versus traditional tonsillectomy: A double blind randomized controlled trial. J Res Med Sci. 2012 Jan; 17(1): 45-50.

[10] Mitic S, Tvinnereim M, Lie E, Saltyte BJ. A pilot randomized controlled trial of coblation tonsillectomy versus dissection tonsillectomy with bipolar diathermy haemostasis. Clin Otolaryngol. 2007; 32(4): 261-7

[11] Noordzij JP, Affleck BD, Coblation versus unipolar electrocautery tonsillectomy: a prospective, randomized, single-blind study in adult patients. Laryngoscope. 2006 Aug;1 16(8):1303-9.

[12] Paradise JL: Tonsillectomy and adenoidectomy. In Bluestone CD, Stool SE, Alper CM, et al (eds): Pediatric Otolaryngology 4th ed. Philadelphia, W. B Saunders:12101222,2002

[13] Polites N, Joniau S, Wabnitz D, Fassina R, Smythe C, Varley P, Carney AS. Postoperative pain following coblation tonsillectomy: randomized clinical trial. ANZ J Surg. 2006; 76(4): 226-229.

[14] Temple RH, Timms MS. Paediatric coblation tonsillectomy. Int J Pediatr Otorhinolaryngol. 2001; 61(3):195-8.

[15] Weir N. History of Medicine: Otorhinolaryngology. Postgrad. Med. J. 2000;76:65-69.

[16] Wagner J, Einfluss des Coblation $₫$-Verfahrens bei der Tonsillektomie auf die Häufigkeit von Nachblutungen und postoperativen Schmerzen, Dissertation zur Erlangung des Grades eines Doktors der Medizin der Medizinischen Fakultät der Heinrich-Heine-Universität Düsseldorf, Hals- NasenOhren- Klinik der Heinrich-Heine-Universität Düsseldorf, Germany.

[17] Windfuhr JP, Chen YS, Remmert S. Hemorrhage following tonsillectomy and adenoidectomy in 15,218 patients. Otolaryngol Head Neck Surg. 2006; 132:281-286.

[18] Young J. R, Bennett J. History of Tonsillectomy. ENT News. 2004; $13: 34-35$. 